\title{
Sobre el papel de la política en la comprensión modernista del origen de las naciones: Ernest Gellner frente a Paul Brass
}

\author{
M odesto Guillermo Gayo Cal \\ Universidad de Santiago de Compostela \\ Facultad de Ciencias Políticas y de la Administración \\ C ampus Universitario Sur, s/n. 15706 Santiago de Compostela \\ modesg@excite.es \\ modusces@usc.es
}

\section{Resumen}

Se ha discutido largamente, en la literatura sociológica y politológica, sobre el origen de las naciones y los nacionalismos. Anthony $\mathrm{D}$. Smith decidió agrupar a un amplio conjunto de autores bajo lo que denominó el «paradigma modernista», reuniéndolos por su defensa del origen moderno de los nacionalismos. Este trabajo quiere hacer patente la heterogeneidad presente en su interior, al dedicarse a la exposición de dos lógicas explicativas diferentes incluidas por Smith en el modernismo.

Palabras clave: instrumentalismo, nación, nacionalismo, modernismo.

\section{Abstract}

It has been discussed for a long time in sociology and political science about the origins of nations and nationalisms. Anthony D. Smith decided to gather a wide group of authors under what he called the modernist paradigm, united by their defense of the modern origin of nationalisms. This work wants to assert the internal heterogeneity of that paradigm, showing two different explanatory logics that Smith includes in modernism.

Key words: instrumentalism, nation, nationalism, modernism.

\section{Sumario}

Introducción Conclusiones

Ernest Gellner: la nación económica Bibliografía

y la ausencia de la política

Paul Brass: la nación como instrumento 


\section{Introducción}

Anthony D. Smith ha insistido en dividir la literatura compuesta por todas las aportaciones que se enmarcan dentro de la teoría del nacionalismo en varios paradigmas. Uno de ellos es el modernismo, en el seno del cual se defendería el origen moderno de las naciones y los nacionalismos. Su modernidad significa que no es posible atribuir a un pasado premoderno las razones por las cuales emergen. Es, principalmente, después de la Revolución Francesa de 1789 cuando los movimientos nacionalistas cobrarán sentido a través del surgimiento de una nueva ideología. Antes no pudieron existir, puesto que ni siquiera podían ser pensados. D esde esta perspectiva, se cree firmemente en el profundo impacto que las transformaciones de los siglos XVII y XVIII tuvieron en las sociedades hasta ese momento constituidas, y que empezarían a ser entendidas como sociedades tradicionales. Las sociedades modernas se diferenciarían con claridad de sus predecesoras y darían lugar a nuevos fenómenos, imposibles en contextos previos. Lo que se produce es una ruptura que apenas admite pensar en la continuidad y la supervivencia de lo antiguo.

Sin embargo, y ésta es una de las tesis centrales de este trabajo, decir que un autor es modernista no resulta demasiado informativo. Incluso Anthony Smith, consciente y voluntariamente ubicado fuera del modernismo y representante sobresaliente del paradigma etnosimbólico, defenderá la modernidad de las naciones y los nacionalismos desde un punto de vista organizativo e ideológico, lo cual no es poco. El punto que ha de ser resuel to es la determinación de la importancia de las identidades premodernas para la constitución de las identidades nacionales e igual mente la persistencia de las mismas y su moldeabilidad. L os modernistas hablan de las identidades, pero rechazan su inmutabilidad, afirmando la capacidad de las élites para manipularlas casi a su antojo; más bien, se trataría de un instrumento en manos de éstas últimas. Para clasificar a los teóricos del nacionalismo puede haber criterios más relevantes y sustantivos que el recurso a los extraídos de tesis o principios general es comunes a una gran cantidad de investigadores. El que un criterio agrupe a muchos nada quiere decir por su mismo número, si lo que deseamos es construir una tipología que nos ayude a comprender el trabajo realizado en un ámbito de estudio determinado. Es conveniente, en este sentido, recurrir a los mecanismos clave y a las tesis fundamentales, a las lógicas explicativas igual que a las conclusiones. Antes de ello, es necesario hacer un repaso amplio de la literatura científica para poder discriminar cuál o cuáles entre los criterios posibles es 0 son especialmente significativos. No basta hablar del modernismo, dado que podemos encontrar diferencias igual mente significativas entre Anthony Smith y Ernest Gellner como entre éste último y Paul Brass. Este trabajo lo dedicaré a presentar dos teorías y lógicas explicativas distintas y el papel que la política desarrolla en cada una de ellas como ilustración y conclusión de todo ello. Gellner y Brass son los autores analizados por pasar por ser dos modernistas en sentido estricto, por la relevancia de sus aportaciones y porque éstas permiten observar con gran claridad la heterogeneidad que el modernismo esconde. 


\section{Ernest G ellner: la nación económica y la ausencia de la política}

Es sorprendente observar cómo uno de los autores a los que más referencia se ha hecho como defensor de un modernismo extremo, asfixiante de toda identidad inmemorial y portador de una teoría que dotaba al nacionalismo con una naturaleza generadora, de naciones, apenas se puede afirmar que haya sido cabalmente comprendido. En realidad, no hay naciones sin nacionalismo, pero la capacidad que el movimiento político nacionalista tiene para activarse es íntimamente dependiente del contexto que le da cobertura. $\mathrm{H}$ abría que decir, por tanto, que sin la movilización producto de la actividad de los nacionalistas no surgen las naciones, y, siendo insoslayable esta segunda parte, sin las transformaciones sociales conocidas como «industrialización» no se habrían activado los nacionalismos.

Según G ellner, el nacionalismo es un fenómeno de la modernidad. Surge sólo cuando se dan las condiciones necesarias para su existencia, esto es, el nacionalismo es uno de los productos de unas condiciones de existencia muy concretas e históricamente únicas. En términos absolutos, naciones y nacionalismos son accidentales y/o contingentes, pero, dado el desarrollo histórico que se ha producido, han terminado por ser elementos necesarios de un modelo de sociedad en cuyo seno deben satisfacerse determinados requisitos funcionales. Ambos tienen una finalidad social, relacionada con la conservación de la sociedad y, en este sentido, de su economía. En consecuencia, nos encontramos con una explicación que puede ser etiquetada como funcional-estructuralista, en el sentido de que convierte al objeto de análisis en un elemento explicado por su funcionalidad para el funcionamiento óptimo de una estructura situada en un plano de desarrollo diferente y del cual se deriva cualquier explicación posible, puesto que todo fenómeno tiene sus raíces en dicho núcleo material generador de existencia.

\section{La premodernidad: una época sin nacionalismos}

En la obra de Ernest Gellner, la modernidad se asocia con el industrialismo, es decir, con la sociedad industrial, y ésta sería entendida como una de las tres etapas fundamentales en la historia de la humanidad. Las otras dos serían las formas preagraria y agraria ${ }^{1}$, él centra su preocupación en la segunda. Por tanto, cuando hablo de la premodernidad me estoy refiriendo fundamentalmente a la etapa agraria de la historia de la humanidad. Se puede decir, siguiendo a G ellner, que esta etapa tiene una serie de características destacables:

1. La sociedad preagraria estaría basada en la caza-recolección; la sociedad agraria, en la agricultura, y la sociedad industrial tendría un carácter científico-industrial. Con esta observación tratamos de incorporar la terminología empleada en N acionali smo (1998). 
1. Se inicia un proceso progresivo de alfabetización ${ }^{2}$ y surge y se consolida un estamento culto ${ }^{3}$ encargado de dirigir ese proceso. La alfabetización permite acumular y centralizar información, pudiendo ser entendida ésta como cultura y conocimiento. Sin embargo, la mayoría de la población, fundamental mente rural, se mantiene distante de ese proceso alfabetizador, de manera que la socialización de los miembros de la sociedad agraria está canalizada a través de la multitud dispersa de comunidades locales. Los individuos se reproducen más bien a través de la imitación. Esta diferencia entre los alfabetizados y los que se socializan fuera de tal proceso es la distancia que existe entre la «al ta cultura» y la «baja cultura», las cuales funcionan como dos polos enormemente distantes, es decir, la discontinuidad entre culturas en el seno de una misma sociedad será un rasgo característico. Sin duda, son las condiciones materiales de existencia las que provocan este abismo, más que la intencionalidad política de las élites dominantes.

2. El poder y la cultura/conocimiento se centralizan: poder y cultura actúan por separado, en el sentido de que no confluyen necesariamente en el escenario político. Las doctrinas y la práctica política no exigen su convergencia. D e hecho, en el ámbito social, pero con trascendencia política, la cultura es más un criterio diferenciador de los distintos estratos sociales y sus funciones y/o ocupaciones que un elemento aglutinador del conjunto delos miembros de la comunidad en régimen de igualdad 4 . La desigualdad de estatus no sólo se admite, sino que es esencial. La división del trabajo y la estructura social ${ }^{5}$ se insertan en este marco cultural caracterizado por la divi-

2. Entendida como «el establecimiento de una escritura hasta cierto punto permanentey normalizada» (G ellner, 1988, p. 22). Con ello no se está refiriendo a la alfabetización de la población, a la capacidad de ésta de leer, escribir e incluso comprender la lengua propia normativizada, en mayor o menor medida, sino que centra su atención en la normalización de una lengua a nivel escrito, es decir, en el desarrollo de la escritura y su consolidación.

3. Será habitual que ese grupo considerado intelectualmente superior se identifique o esté relacionado con alguna religión, lo cual lleva a Ernest G ellner a hablar de una «clerecía».

4. En la sociedad agraria, como tipo ideal, el elemento cohesionador es la estructura, por lo que la cultura no tiene ese papel. Ésta refuerza lo que la estructura dicta, pero no constituye nada por sí misma. En consecuencia, cultura y estructura vivirían en armonía: una estructura compleja, consolidada y desigual itaria, se correspondería con una cultura compartimentada y protectora de la diversidad de estatus. Por tanto, no sería necesaria la presencia de una cultura compartida por el conjunto de la población; es más, esto sería contraproducente. La comunicación sería posible por la fortaleza de la estructura, que funcionaría como marco referencial de los mensajes comunicativos.

5. Cuando Ernest G ellner habla de estructura social y de división del trabajo, en la práctica está hablando de lo mismo. Considera que la complejidad de aquéllas es una característica propia tanto de la sociedad agraria (a la que en algunas ocasiones añade el adjetivo de «avanzada») como de la sociedad industrial, dado que la división del trabajo era compleja en ambos casos. Por el contrario, no podemos decir lo mismo de la sociedad preagraria, centrada en la caza y la recolección, en la que la división del trabajo, aun existiendo en al guna medida, estaba menos desarrollada. 0 tra cosa es el tipo de división del trabajo, su papel en la sociedad (por ejemplo, con respecto a la cohesión de la misma) y la relación que mantiene con la cultura, siempre pensando desde un punto de vista funcional. 
sión de esta índole (cultural). La cultura no define las fronteras políticas, sino que opera en la política bajo el imperio de otros criterios. Lo habitual es que una organización o unidad política incorpore diversas comunidades culturalmente disímiles y/o distantes. Si la cultura y la política no confluyen, si cada una actúa por su lado, difícilmente podría aparecer y mucho menos triunfar el nacionalismo ${ }^{6}$.

3. La sociedad agraria, como ya he dicho, está internamente dividida desde el punto de vista cultural. El estrato más elevado, la élite 7 , no sólo se distingue culturalmente, sino que también se esfuerza porque así sea. La diferenciación cultural es beneficiosa para la conservación del poder y la legitimidad de las posiciones de tal índole. Pero la diversidad cultural no se refiere sólo a una dimensión social vertical o estratificadora, sino también a la existencia de múltiples comunidades culturales, las cuales conviven sin grandes problemas ni conflictos en relación con la propia existencia de la diferencia. Por tanto, la complejidad cultural es notoria; al igual que lo es la división del trabajo, también compleja.

4. Generalmente, los mensajes sólo tenían sentido en el seno de las comunidades, esto es, la comunicación requería una referencia a un contexto conocido. El significado está integrado en ese contexto, y apenas va más allá, de manera que se aproxima a la abstracción y la impersonalidad.

5. Las unidades políticas características son las comunidades locales en régimen de autogobierno, los grandes imperios y una combinación de ambas basada en una autoridad central común y autonomía para un conjunto de unidades locales. Su existencia se remonta a cinco mil años atrás. En la etapa agraria apenas se puede hablar de la existencia de naciones, aunque sí hubo estados, por lo que se dio el patriotismo, y no el nacionalismo.

6. Lo que Ernest G ellner pretende dejar claro es que la función de la cultura cambia de la sociedad agraria a la industrial. En la primera, suscribe y legitima una división social vertical de tareas basada principalmente en la adscripción. En la segunda, la cultura funciona como un criterio trazador de las divisiones horizontales-espaciales, esto es, distinguiendo a la comunidad hacia fuera y cohesionándola hacia dentro. Pero no se trata únicamente del cambio funcional sufrido por la cultura, sino que ambas funciones no podían convivir en el tiempo, eran mutuamente excluyentes: la cultura como nación quiebra la cultura como estatus específico y diferenciado dentro de la sociedad. Visto así, no es difícil col egir la imposibilidad de la explosión nacionalista en la sociedad agraria.

7. En la época agraria no cabe hablar de una élite en términos simples y siempre idénticos. L os estratos superiores varían en los diferentes casos por razones de tamaño, organización, y otros. En este sentido, Ernest G ellner subraya que esta minoría se diferencia según una serie de oposiciones: centralizada/no centralizada, castrada/semental, cerrada/abierta y fusionada/especializada.

8. Ernest Gellner (1988) ha entendido queel nacionalismo es una forma específica de patriotis mo, por lo queal hablar del primero estaríamos haciendo referencia a un subtipo del tipo principal, éste último, el patriotismo. Sin embargo, cuando en Cultura, identidad y política (1993a) afirma que en la antigüedad hubo patriotismo y estados pero no naciones, parece darnos a entender que el patriotismo es una forma de afectividad positiva ligada al Estado, y que no se refiere a las naciones. Así, podría colegirse que la forma de afectividad que se liga a las naciones es el nacional ismo como al go distinto. El problema es que para G ellner naciones y estados son 
6) Desde un punto de vista sociopolítico, el dominio está en manos de una minoría guerrera y escriba, de la nobleza y el clero, cuyo dominio y/o control es ejercido sobre una gran mayoría dedicada a la producción agrícola, dispersa en una multitud de unidades locales apenas comunicadas. En este sentido, encaja perfectamente la presencia de un sistema jerárquico de posiciones sociales ${ }^{9}$.

7) Ú nicamente la clerecía ${ }^{10}$ está implicada en alguna forma de política abiertamente cultural. Ésta tenía una pretensión de conservación y transmisión, pero carecía de toda posibilidad de al canzar la homogeneización, puesto que fal taban los medios que ello exigía.

8) Si consideramos las bases materiales de esta sociedad, según Gellner, podemos decir que «Las sociedades agrarias se basaban en la producción de alimentos y su posterior almacenamiento, así como en una tecnología relativamente estable. Prácticamente ésta es la definición de una sociedad agraria» (Gellner, 1998, p. 39). Dado el práctico estancamiento tecnológico y la escasez de recursos disponibles, la producción encontraba su límite cuantitativo y cualitativo, aunque no así el crecimiento de la población ${ }^{11}$.

\section{La modernidad: las razones del nacionalismo}

En realidad, para la compresión del nacionalismo y la explicación de su surgimiento, G ellner entiende la modernidad como industrialismo. La época moderna es la era del desarrollo industrial, de la formación de una nueva sociedad con ese carácter, la cual produce un amplio conjunto de fenómenos, entre los que está el nacionalismo. En consecuencia, éste es propio de la modernidad, y será en esta época cuando tendrá sus raíces. Para explicar el nacionalismo no será necesario remontarse al pasado más o menos lejano de las distintas comunidades, sino estrictamente comprender la lógica interna ${ }^{12}$ de desarro-

difícilmente separables, tanto lógica como históricamente. $\mathrm{H}$ ay un vínculo de partida, el cual nos permite considerar al nacionalismo una forma de patriotismo que abraza a la nación y al Estado, dado que ambos se imbrican simbióticamente para facilitar su supervivencia.

9. En este sistema jerárquico destaca la adscripción de posiciones sociales en función de la herencia, familiar o relacionada con el parentesco, y de la relación personal con el poder, más que la adquisición individual de las posiciones siguiendo un criterio meritocrático. Como afirma el propio G ellner: «En estas sociedades, la condición social, la posición que se ocupa y los derechos que ésta proporciona son los que determinan el destino de un individuo» (G ellner, 1998, p. 41-42).

10. Entendida como estrato sacerdotal, por lo tanto con vínculos religiosos y/o sagrados.

11. Q ue el crecimiento de la población pueda dispararse, al mismo tiempo que la capacidad productiva apenas varía, es lo que lleva a G ellner a considerar a la sociedad agraria una sociedad malthusiana.

12. Éste es el sentido quetienen las siguientes palabras de Gellner: «Tenemos que preguntarnos qué clase de estructura es la que conduce a un culto consciente de la cultura, [... ] y la que conduce a la estandarización compulsiva de la cultura dentro de la unidad política» (G ellner, 1993a, p. 39). El culto de la cultura propia es una forma de referirse al nacionalismo. 
Ilo y funcionamiento de la sociedad industrial ${ }^{13}$. Conviene, por tanto, empe zar indicando al gunos de los rasgos constitutivos de esta sociedad:

1) Triunfa la racionalidad por encima de cualquier otro criterio de pensamiento y acción. La razón, pensada principalmente en términos científiCOS, ha de ser una guía básica para el desarrollo de la sociedad e impregnar también el nivel individual correspondiente a sus miembros. N o en vano, su sistema productivo se basa en la acumulación de ciencia y tecnología. Al mismo tiempo, tanto la sociedad moderna y/o industrial como su organización política necesitan la innovación tecnológica para asegurar su supervivencia.

2) La división del trabajo es compleja y cambiante. La complejidad se refiere fundamentalmente al grado de especialización alcanzado, muy elevado. El cambio tiene un significado de movilidad ${ }^{14}$ en su seno, lo cual afecta positivamente a la igualdad dentro de la sociedad ${ }^{15}$, y quiere significar igualmente un crecimiento y un desarrollo permanentes.

3) Existe, o se fomenta la construcción de, un sistema educativo general o universal que incorpora a los miembros a una cultura 0 a un sistema de ideas determinado ${ }^{16}$. Aunque sus tareas serán concretas y especializadas, la educación recibida tendrá un carácter general y estandarizado. Así, los individuos son alfabetizados en masa de un modo similar ${ }^{17}$, Io cual los incor-

13. El enfoque modernista de Ernest $G$ ellner parte de los supuestos teóricos. El camino contrario, es decir, avanzando desde los datos, es el que Anthony D. Smith trata de recorrer. Arrancar desde la teoría, como un presupuesto, Smith lo considera uno de los rasgos del paradigma modernista considerado como mito.

14. La movilidad se refiere principalmente a la capacidad de los individuos o miembros de la sociedad para cambiar de ocupación a lo largo de su vida; para lo cual se requiere la adquisición de una formación compleja caracterizada por la interiorización de una cultura alfabetizada y desarrollada, que permita la incorporación a un intercambio comunicativo abstracto o no contextualizado de amplitud comunitaria o social (la comunidad o la sociedad pensadas en términos de unidad cultural y/o económica, esto es, lo que será pensado como nacional).

15. La igualdad se refiere, entre otras cosas, a la existencia de un sistema de estratificación continuo, sin cortes radicales o distinciones insuperables.

16. La construcción de un sistema educativo de alcance nacional debe entenderse como un desarrollo necesario y no como una opción entre otras. La lógica de funcionamiento, crecimiento y conservación del sistema económico así lo exige. Por ello, en Thought and Change (1964) concluía que para el funcionamiento de una sociedad industrial era necesario un tamaño mínimo, la nación, puesto que G ellner parece sobrentender que existe un tamaño mínimo de las naciones y que es precisamente a partir de ese umbral que los sistemas económicos que sostienen a las sociedades pueden desarrollarse: las naciones tienen el tamaño funcionalmente necesario para el desenvolvimiento de las sociedades industriales. Curiosa coincidencia teórica, empíricamente fal seada 0 aplastada.

17. El sistema educativo no pretendetan sólo capacitar a los miembros de la comunidad nacional para cumplir con sus tareas en el mundo económico-laboral, sino que busca, además de la pericia técnica y/o el adiestramiento alfabético, su lealtad. 
pora a la «alta cultura» ${ }^{18}$ alfabetizada de la que previamente se véan excluidos. Es la alfabetización, al mismo tiempo, una exigencia básica para la consecución y el sostenimiento de una ciudadanía completa, esto es, para ser miembro de una comunidad moderna de un modo efectivo ${ }^{19}$. Además, podríamos incluir como elemento adicional, en línea con lo sostenido por Gellner en Thought and Change (1964), que la alfabetización se realiza en una lengua concreta, lo cual sienta un el emento de diferenciación desde el principio ${ }^{20}$. Los individuos se incorporan plenamente a una comunidad a través de la internalización de su alta cultura, por lo que su identidad se relacionará con la cultura o, pensado en otros términos, la etnia, es decir, la etnicidad será la principal fuente de identidad, una vez ha sido abandonada definitivamente, al menos de un modo socialmente significativo, la identidad fruto del parentesco, propia de la sociedad agraria.

4. La división del trabajo, fundamentalmente a través del sistema educativo universal, será la encargada de socializar a los miembros de la sociedad, de su reproducción. La socialización es una tarea de la sociedad como un todo, no de sus subcomunidades. Por tanto, el método reproductor es centralizado en su estructura21.

5. Los trabajos desempeñados están más centrados en la manipulación de significados que de objetos.

6. La comunicación sin referencia al contexto es continua y necesaria. LoS extraños deben poder comunicarse, y para ello es necesario el aprendizaje generalizado de un código lingüístico-cultural abstracto ${ }^{22}$ que pueda ser

18. G ellner afirma que esta «alta cultura» debe incorporar una lengua y unas reglas de comportamiento, y posee una marca étnica.

19. En Thought and Change (1964) insiste en que la alfabetización en la lengua favorecida sería la base no sólo de una ciudadanía efectiva, sino también de la identificación y la lealtad.

20. Lo importante, siguiendo lo expresado por G ellner en Cultura, identidad y política (1993a), para el nacionalismo y los nacionalistas no es tanto la diferenciación cultural y/o lingüística como la conciencia difundida de la diferencia y sus implicaciones sociopolíticas (p. e.: el orgullo de pertenencia). La conciencia importa tanto como el hecho, esto es, lo subjetivo y lo objetivo tienen un papel destacado. En este caso, es crucial determinar la relación que entre ambos polos se da y cuál(es) es el elemento de desarrollo sobre el que se asientan, ya sea idéntico en ambos casos, ya divergente. Verdaderamente, decir que lo subjetivo tiene un papel principal en el desarrollo del nacionalismo, y no sólo como pura manifestación de un proceso que se sustantiva o cristaliza en otro lugar, puede quebrar, en parte, la construcción teórica modernista de G ellner, basada en las condiciones socioeconómicas de la sociedad, y elusiva con respecto a la presencia teórica de los mitos, los valores, los sentimientos y los recuerdos que en una determinada comunidad se comparten. Éstos son compartidos, pero por razones que poco tienen que ver con ellos mismos, y son concebidos como in-auténticos, falsos o puramente inventados. El nacionalismo tiene otras raíces, aunque utilice y frecuentemente manipule lo que los individuos como miembros de una comunidad piensan.

21. O bviamente, se está hablando del método educativo, no de la estructura de la sociedad.

22. Ésta es una referencia directa a la necesidad estructural de la alfabetización general de la población para el funcionamiento de la sociedad industrial. 
utilizado para la emisión y la descodificación de mensajes carentes de referencias externas directas. Es tan importante que exista el medio lingüístico estandarizado y generalizado como los medios materiale ${ }^{23}$ que posibiliten o favorezcan la propia comunicación, aunque es obvio que la existencia de éstos últimos es una condición necesaria para la constitución del primero. En la modernidad se cumplen ambos requisitos. D e este modo, puede propagarse cualquier tipo de idea o doctrina, un ejemplo de lo cual fue el surgimiento y la generalización del nacionalismo.

7. El dominio de este código lingüístico abstracto y, en relación con ello, su preparación de carácter general, otorgan a los miembros de la sociedad una flexibilidad y/o una movilidad en la estructura ocupacional necesarias para el propio funcionamiento de la sociedad y su economía. Además, la movilidad favorece la igualdad ${ }^{24}$ entre aquéllos, a través de sus exigencias educativas ${ }^{25}$, por lo que la ciudadanía también sale beneficiada ${ }^{26}$. En consecuencia, en una sociedad en la que la ciencia tiene un papel clave y la

23. Integrados en estos medios materiales encontramos a los grandes medios de comunicación, característicos de la modernidad.

24. El reconocimiento de la igualdad formal no es más que un reflejo de la movilidad ocupacional. $\mathrm{D}$ e todos modos, la igualación no puede quedarse en el terreno de lo formal, puesto que de lo contrario no se daría la convergencia cultural que el sistema productivo industrial exige. N o obstante, la confluencia en una cultura común se restringe al ámbito de la educación no especializada, por lo que no podemos esperar una homogeneización total. La sociedad industrial, por tanto, requiere igualdad y diferencia, pero una diferencia construida a partir del asentamiento de unos mínimos culturales igualadores.

25. D ebemos subrayar que este tipo de sociedad exige una adecuación notable entre la formación de los individuos y los trabajos a desarrollar, por lo que la adscripción de individuos a trabajos según un criterio estocástico o azaroso no puede ser entendida más que como una posibilidad residual y en camino de extinción.

26. G ellner afirma que existe un punto de inflexión en la historia humana reciente a partir del cual se ha originado una tendencia imparable hacia el igualitarismo, tras siglos y/o milenios de desigual dad creciente. Para animar esta corriente igual itarista, han surgido una serie de factores de carácter principalmente sociopolítico:

1) La movilidad.

2) La naturaleza de nuestra vida de trabajo.

3) N uestra vida de hogar.

4) La nueva división cultural del trabajo y los medios de comunicación.

5) U na vulnerabilidad menor.

6) La educación uniforme y la socialización.

7) La índole de la riqueza en la sociedad industrial opulenta.

8) El trabajo ético.

9) La naturaleza del poder.

10) La deliberada igualación desde arriba.

11) El igualitarismo como camuflaje.

12) El talento específico que exigen muchos puestos.

13) El empobrecimiento ideológico.

14) El positivo aval filosófico de la igualdad.

Algunos de estos factores han sido incorporados en la descripción de la sociedad industrial, pero aquí únicamente son enumerados, puesto que su análisis nos llevaría más allá de los objetivos de este trabajo. 
innovación tecnológica es una condición para su continuidad histórica, la movilidad ocupacional emerge como un elemento insustituible e inherente a la propia lógica de la sociedad, y la igualdad formal es una de sus derivaciones.

8. D e todo lo anterior se colige que urge la existencia de una cultura común desarrollada y/o alfabetizada dentro de la cual sea posible la comunicación que permita la subsistencia de la sociedad industrial y de la forma de vida de sus miembros: «La necesidad de la homogeneidad cultural deriva de las exigencias de una comunicación rápida, fácil y precisa, de la posibilidad de transferir rápidamente a las personas a nuevos roles económicos, deriva de una división del trabajo rápidamente cambiante, compleja, refinada» (G ellner, 1993a, p. 125). La cultura es el principio cohesionador de esta sociedad ${ }^{27}$, y ya no la estructura ${ }^{28}$, la cual se debilita y sufre una erosión considerable. Podría decirse que la primera sustituye en sus funciones a la segunda ${ }^{29}$, si bien sólo sobrevivirán las culturas desarrolladas.

9. Ú nicamente la existencia de un estado puede asegurar la presencia de esa cultura homogénea y compartida ${ }^{30}$. Aquél es el soporte necesario de ésta

27. A pesar de la insistencia de $G$ ellner en el papel absolutamente central de la cultura como elemento vertebrador de la sociedad, una vez constatada teóricamente la incapacidad de una estructura compleja y móvil para realizar la misma función, no debemos olvidar que en Thought and Change (1964) subrayaba la existencia de una estructura sólida en las sociedades modernas cristalizada en la burocracia, la cual vendría a sustituir a los lazos de parentesco de las sociedades previamente existentes, basados en un criterio de adscripción y no de elección o mérito (la mayor o menor relevancia de un aspecto u otro en las diferentes socie dades debe entenderse de un modo relativo y no como presencia o ausencia absoluta, 0 exclusión necesaria). Esto, sin embargo, no debe oscurecer que el predominio de la cultura ya era afirmado con decisión en esa obra temprana. En esta cuestión el pensamiento de G ellner apenas sufre ninguna modificación significativa: la relación entre cultura y estructura se mantiene en el tiempo en los términos indicados de predominio cultural durante el industrialismo.

28. La diferenciación entre cultura y estructura la extrae $G$ ellner de la obra de Radcliffe-Brown. C ree que puede ser utilizada como un criterio guía que nos indique qué puede ser estudiado y comprendido, qué puede ser comparado y qué es susceptible de ser generalizado. Por estructura debemos entender «el sistema relativamente estable de roles o posiciones y las tareas y actividades asignadas a ellos que real mente forman una sociedad» (G ellner, Cultura, identidad y política, 1993a, p. 23). En su última obra, Nacionalismo (1998), mantiene el término cultura, pero se inclina por el empleo de organización en lugar de estructura, aunque el concepto no parece sufrir un cambio significativo. Entonces, encontramos que pasará de hablarse del binomio social cultura/estructura a uno con apariencia de novedad: cultura/organización.

29. La idea de reemplazamiento o sustitución es destacada con claridad en Thought and Change (1964).

30. D ebe ser observado que esta cultura exige no sólo la existencia de un sistema educativo que la fomente y la sostenga, sino también de una lengua común. En buena medida, lo que se comparte es la lengua; no olvidemos que $G$ ellner entiende la cultura principalmente como lengua, al menos en los hechos, si no en el concepto. 
y, a su vez, la necesita para asegurar su propia supervivencia ${ }^{31}$. Esto sugiere otro de los rasgos de la sociedad moderna o industrial, la centralización del poder, 0 , lo que es lo mismo, la concentración del mantenimiento del orden en pocas manos. Además, el Estado dedica sus esfuerzos protectores y animadores no sólo a la cultura, sino también a la economía propia. En realidad, el lazo entre Estado y cultura viene determinado por las necesidades impuestas por el desarrollo económico: Estado y cultura tienen la razón de su nexo en la economía moderna ${ }^{32}$.

U na vez caracterizados ambos tipos de sociedad, la agraria y la industrial, ha podido observarse que el corte radical que existe entre ellas es evidente, por lo que el espacio para la continuidad apenas existe, y se incluyen en la profunda ruptura las consecuencias sobre las identidades sociales y políticas pre-modernas. Por otro lado, la sociedad industrial no es una opción entre otras, sino que ha sido la tendencia de desarrollo social que ha triunfado en la humanidad como conjunto, si bien de un modo desigual. El nacionalismo surge en el seno de este proceso de industrialización generalizado, por lo que debe ser comprendido, explicado y analizado sobre ese trasfondo. En la transición de la sociedad agraria a la sociedad industrial surge el nacionalismo, y son los rasgos de esta nueva sociedad los que lo provocan ${ }^{33}$. El nacionalismo no es el resul-

31. No en vano, la cultura legitima al Estado y le suministra sus símbolos. H ay que añadir, sin embargo, que el principio nacional, entendido como cultura, tal como Gellner hace, no es el único pilar del Estado. Éste recibe su legitimidad de tal principio junto con el fomento y la presencia efectiva de la prosperidad económica. Lo que resta por saber es la relación entre ambos pilares del Estado. Por un lado, la tesis difusionista de la desigualdad nos propondría una relación inversa, esto es, a menor prosperidad económica relativa, mayor relevancia del nacionalismo (dejamos de lado los problemas que plantea a la hora de abordar el desarrollo de los nacionalismos en los países más desarrollados). Pero, por otro lado, no vemos cómo se puede derivar de su teoría, tal como él ha defendido, sobre todo a un nivel prospectivo o de futuro, que una mayor prosperidad amortigua la fiebre (utilizo el término fiebre dado que $\mathrm{G}$ ellner ve el nacionalismo más como un problema, o incluso una enfermedad, que como una oportunidad) nacionalista. Ante esta dificultad, parece apuntar la idea de la desigualdad de la prosperidad, si bien en un contexto industrial. N o obstante, los problemas teóricos, y no hablo de los empíricos, no se resuelven, dado que encontramos serias trabas para combinar este argumento de la difusión desigual con el del nacionalismo derivado del análisis de las condiciones de funcionamiento y supervivencia de una sociedad moderna o industrializada. Por tanto, vemos como la legitimidad del Estado está sostenida por dos piernas que admiten distintas disposiciones.

32. Es notable que en esta caracterización de la sociedad industrial, que he intentado que incorporase los rasgos centrales de tal época sostenidos a lo largo del conjunto de su obra, aunque fundamental mente basándome en $\mathrm{N}$ aci ones y naci onali smo (1988), no se haya incluido la aparición sobresaliente del proletariado industrial y de la intelligentsia, según Gellner, en su formulación de 1964, las puntas de lanza del nacionalismo. Es más, su presencia resulta necesaria para que el nacionalismo se desarrolle, aunque, una vez alcanzada la independencia, sus destinos y horizontes vitales varíen en función de la ubicación en uno u otro polo del espectro socionacional.

33. La sociedad industrial o el desarrollo del industrialismo no provocan únicamente la aparición del nacionalismo. Existen otros fenómenos que también enraízan su existencia en los 
tado de una historia de las ideas más o menos casual, sino una doctrina necesaria derivada de las nuevas condiciones sociales englobadas bajo el industrialismo naciente. D icho en términos simples, el industrialismo reclama el nacionalismo. Son las necesidades del primero las que exigen la presencia del segundo: «EI nacionalismo tiene un profundo arraigo en las exigencias estructurales distintivas de la sociedad industrial [... ] el movimiento es la manifestación externa de una profunda modificación en las relaciones entre gobierno y cultura, modificación que es además inevitable» (Gellner, 1988, p. 53). El gobierno/Estado y la cultura deben vincularse, debido al desarrollo necesario de la exosocialización ${ }^{34}$ por razones estructurales de la nueva sociedad industrial. Sólo la presencia efectiva de un estado puede asegurar la homogeneización y la homogeneidad cultural, y únicamente una cultura generalizada de tal tipo puede crear las condiciones y permitir el desarrollo de la industrialización y/o de la nueva forma de organización social, la sociedad indus trial. En los términos de G ellner, al modo de una paráfrasis, la sociedad industrial, para su supervivencia, necesita la existencia de un crecimiento económico y éste, a su vez, requiere un crecimiento cognitivo. Por su parte, los miembros individuales de la nueva sociedad absorben el cambio, es decir, aceptan la cultura desarrollada alfabetizada compartida por la comunidad de pertenencia, porque, tras la erosión de las viejas estructuras, en la época moderna únicamente la educación puede proporcionarles identidad, dignidad y seguridad material ${ }^{35}$. Visto así, los individuos deben preocuparse por fijar y fomentar la congruencia entre su cultura y la del Estado o de la burocracia, lo que es lo mismo que ser nacionalista. El fenómeno nacional explota en un mundo de estados en el cual los individuos compiten por el acceso a los recursos estatales y/o públicos ${ }^{36}$. Si esto es así, la presencia del Estado es crucial en todo el proceso nacionalizador. El nacionalismo es un derivado de todo ello: las condiciones objetivas imponen una homogeneidad cultural que favorece

cambios debidos al desenvolvimiento del nuevo tipo de organización social, p. e.: la explosición demográfica, la internacionalización de la economía, la urbanización, la acentuación de la centralización del poder, el colonialismo y el imperialismo. No obstante su vínculo primario con el industrialismo, no por ello dejan de tener una relación muy directa con el propio desarrollo del nacionalismo. En este sentido, por ejemplo, el colonialismo es un antecendente lógico e histórico de la descolonización. Industrialismo y nacionalismo no se oponen o excluyen, sino que se implican, igualmente, lógica e históricamente.

34. G ellner entiende por exosocialización la educación de tipo moderno, esto es, recibida a través de un sistema educativo estatal centralizado.

35. No en vano, la educación podía ser un recurso esencial para acceder a las, frecuentemente nuevas, oportunidades de empleo. Pero además del empleo, la supervivencia fisicomaterial también puede ser relacionada con la defensa de lo propio, es decir, de la comunidad y sus miembros.

36. La distribución de los recursos públicos afecta al conjunto de las políticas del Estado, y los individuos tendrán un contacto directo con este reparto a través de sus oportunidades relativas de acceder a un cargo o empleo público, aunque ésta no sea la única forma en que se experimenta individual mente el flujo de lo público a lo privado de los recursos estatales y/o públicos. 
el surgimiento de tal fenómeno nacional ${ }^{37}$. El propio nacionalismo exige la uniformidad de la cultura. Según G ellner, esto demuestra su debilidad, puesto que la homogeneidad defendida por el nacionalismo sería tan sólo el refle jo de una necesidad de carácter estructural, que consiste en que «un estado industrial moderno sólo puede funcionar con una población movible, alfabetizada, culturalmente estandarizada y permutable» (Gellner, 1988, p. 67). EI nacionalismo está obligado a existir, aunque ninguno en particular. El desenvolvimiento de cada nacionalismo concreto dependerá, al menos en buena medida, de las circunstancias locales.

El salto desde la formulación inicial contenida en Thought and Change (1964) a la que después presentará, principalmente en $\mathrm{N}$ aciones y nacionalismo (1988), es significativo, puesto que aunque continúa habiendo un vínculo entre modernización y nacionalismo, la naturaleza del lazo ha cambiado. En esa primera obra, el surgimiento del nacionalismo no está enmarcado en las necesidades estructurales que deben ser satisfechas para el crecimiento de la economía y la conservación de la sociedad industrial, en la forma de un sistema educativo centralizado y universal que sostiene y fomenta una cultura productora de nacionalismo, sino que se trata más bien de los efectos de la difusión desigual de la industrialización. Las desigualdades injustificadas que genera se reflejan en una estratificación social que anima e incrementa las posibilidades del desarrollo de una revolución, y aparece como una solución a la desigualdad la secesión nacional. De este modo, el nacionalismo se desenvuelve con naturalidad, bajo la presión de un mecanismo reactivador, la desigualdad. Este argumento, es decir, el de la difusión desigual de la industrialización o del impacto irregular 0 asimétrico del industrial ismo, vuelve a ser recuperado en sus obras Encuentros con el nacionalismo (1995) y N acionalismo (1998), donde se considera al nacionalismo el reflejo político de una situación de conflicto entre poblaciones provocado por el distanciamiento creciente en rique za y poder que la industrialización conlleva. En otros términos, la agudización de la desigualdad intercomunitaria genera la explosión nacionalista en el marco de la sociedad industrial. De este modo, para defenderse, las comunidades relativamente atrasadas tratarán de crear sus propias unidades políticas, las cuales funcionarán a modo de mecanismos de defensa frente a los ataques externos, ya sean de tipo cultural, militar, comercial y/o económicos, u otros supuestos que pudiesen darse y también resultasen amenazadores, o se sintie se así, para la comunidad de referencia, ahora «nacional». La emergencia de una situación conflictiva, o incluso revolucionaria, formulada en términos nacionales, a menudo ha sido el reflejo de la coincidencia de los criterios de

37. EI nacionalismo surge principalmente debido al desarrollo de la industrialización, aunque no es el único factor en hacer una contribución de tal tenor. O tros factores también importantes son la presencia notable de la burocracia y la religión protestante, ambos tendentes a favorecer la homogeneización cultural y/o lingüística. Sin embargo, aparentemente contradictorio con la importancia de esta religión es el proceso de secularización que se desenvuelve en Europa en la época del nacionalismo. 
clase y étnico. Si la etnicidad se combina con la clase, las posibilidades de una explosión nacionalista, probablemente violenta, se incrementan.

Antes del nacionalismo no había naciones (naturales) en espera de ser descubiertas, sino que había culturas más o menos desarrolladas que se solapaban y se relacionaban; no había pureza cultural, sino mezcla. Las unidades que se han ido constituyendo bajo las nuevas condiciones del industrialismo han sido cristalizadas por la labor del nacionalismo, si bien éste utilizó, o recurrió a, las culturas previamente existentes. Esto provocó el apuntalamiento y el fomento de las culturas más desarrolladas. Las culturas anteriores a la socie dad industrial lucharon por su supervivencia en la nueva situación a través de la protección estatal, pero no todas consiguieron pasar la prueba. D e esta lucha surge uno de los principales tipos de conflicto nacionalista ${ }^{38}$. La relación entre cultura y Estado era necesaria, pero el nacionalismo la convirtió en legítima. El ser se transformó en deber ser: el vínculo es inevitable y, además, bueno. Por otro lado, además de las culturas heredadas, la sociedad industrial se encontró con unidades políticas también de constitución anterior. Es en el seno de las nuevas condiciones de industrialización donde las culturas y las unidades políticas se encuentran, lo cual generó rivalidades de nuevo cuño relacionadas con las pérdidas y ganancias de cada uno de los participantes en el conflicto.

El nacionalismo apareció y con él las naciones. Para la existencia de las segundas se necesita al primero. Dicho en términos negativos, el nacionalismo no es la prolongación política de las naciones naturales. Las naciones son un producto del nacionalismo. Además, como ya hemos afirmado más arriba, el nacionalismo es necesario, por lo que, lógicamente, las naciones han de aparecer obligatoriamente en paralelo al desarrollo de su fenómeno hermano, el nacionalismo. Aunque éste es necesario, ningún contenido concreto de tal doctrina está determinado, por lo que recoge elementos cultural es previos, frecuentemente inventados ${ }^{39}$, que son presentados como el objeto natural que debe ser recuperado y defendido. El verdadero engaño está en que la promoción de una cultura desarrollada tiene poco que ver con las culturas primarias previamente existentes. Se defiende algo nuevo, aunque la legitimidad de su defensa está, al menos en parte, en su antigüedad.

\section{Paul Brass: la nación como instrumento}

Paul Brass se confiesa ubicado dentro del «instrumentalismo», entendido éste como una corriente teórica dedicada al estudio del nacionalismo que otorga

38. El otro tipo se refiere al conflicto que surge cuando las fronteras políticas y las culturales no coinciden.

39. Según G ellner, los mitos propios y característicos del nacionalismo son un claro ejemplo de la distancia entre el discurso nacionalista y la realidad histórica: «La ideología nacionalista está infestada de falsa conciencia» (G ellner, 1988, p. 161). 
un papel central a las élites ${ }^{40}$ y considera a las culturas instrumentos en manos de aquéllas. Su obra mantiene una gran continuidad en esta línea argumental, y trata en todo momento de indagar en las dinámicas que afectan a las élites. D ado que Brass relaciona el nacionalismo, al igual que G ellner, con la aparición del Estado y las políticas que éste desarrolla, debemos situarlo dentro del paradigma modernista, puesto que el Estado burocrático es un fenómeno que caracteriza principal mente a la modernidad ${ }^{41}$. Así, con estos presupuestos, su modernismo e instrumentalismo, que irán siendo desenvueltos y clarificados en paralelo a la exposición de su pensamiento, comenzamos la tarea de análisis y sistematización del producto de sus reflexiones, siempre con una tendencia a centrar nuestra atención en las aportaciones realizadas en torno al origen de las naciones y del nacionalismo.

\section{Los pilares de su propuesta teórica}

Tratando de desentenderse de cualquier tipo de determinismo cultural, Brass enfatiza la vertiente política del nacionalismo y, más en concreto, el papel que las éites representan en su surgimiento y desarrollo. El nacionalismo, por tanto, debe ser entendido como un fenómeno producto del encuentro competitivo ${ }^{42}$ de un conjunto de élites políticas que persiguen ocupar un lugar relevante en el régimen político en el que se encuentran insertas ${ }^{43}$. El nacionalismo y los rasgos de diferenciación cultural que hallan a su disposición para ser manipulados y utilizados en su beneficio, deben ser considerados instrumentos que las élites emplean para conservar o mejorar sus posiciones. D e este modo, Brass entiende que el fenómeno nacional tiene que ser concebido desde una perspectiva instrumentalista. Lo que ello supone es la consideración del nacionalismo como construcción sociopolítica derivada de la actividad desarrollada por las élites políticas, puesto que lo fundamental no son en ningún caso los rasgos culturales que definen o personalizan a un grupo o a una categoría étnicos, ni su longevidad histórica, sino la actitud y la voluntad de las élites y el uso que éstas hacen de todos los recursos que encuentran a su disposición,

40. Afirma Paul R. Brass que «T he term elite [... ] refers to influential subgroups within ethnic groups and classes» (1991a, p. 14).

41. Smith, que pasa por conceder una relevancia crucial a las identidades premodernas, también incorpora al Estado en sus explicaciones como uno de los mecanismos clave que permiten y/o favorecen la transición hacia el nacionalismo. D esde un punto de vista organizativo e ideológico, la modernidad del nacionalismo es indiscutible, pero no se explica por sí mismo, y es su explicación la que obliga a retroceder a tiempos pretéritos, premodernos.

42. D ebe ser subrayado que cuando Paul R. Brass se refiere, y lo hace continuamente, a la competición entre élites, quiere destacar el conflicto que surge de esa dinámica de competencia.

43. N o obstante, es importante resaltar el papel de las alianzas entre élites, puesto que la competencia, además de implicar unas ciertas dosis de conflicto, exige el acuerdo para al canzar el éxito político. La dinámica competitiva estará ligada, por tanto, a redes de alianzas, las cuales serán múltiples y no sólo bidireccionales. 
entre ellos las diferencias culturales. Con ello, y dada la necesidad de la presencia del Estado moderno central izado para su desenvolvimiento, la postura de este autor se caracteriza por su modernismo einstrumentalismo. A partir de estas dos ideas generales, que se derivan con facilidad del análisis de su obra, podremos comprender con mayor facilidad el conjunto de sus tesis y, en primer lugar, su argumento central: «ethnic identity and modern nationalism arise out of specific types of interactions between the leaderships of centralizing states and elites from non-dominant ethnic groups, especially but not exclusively on the peripheries of those states» (Brass, 1991a, p. 8-9, y 1994, p. 111).

U na vez ubicado al autor dentro de la teoría del nacionalismo y expuestos sus pilares teóricos más genéricos, conviene comenzar la tarea de análisis de su pensamiento para aproximarme a su formulación de un modo más detallado, siendo siempre mi referencia el surgimiento de las naciones y el nacionalismo. En este sentido, Brass propone una serie de tesis o argumentos de carácter teórico, congruentes entre sí, que recorrerán todo su estudio y formarán parte de la columna vertebral del mismo, esto es, configuran su propuesta teórica básica, una vez supuestos los principios teóricos generales anteriormente expuestos, y tienen el siguiente tenor:

1. Las identidades étnicas son variables: no surgen necesariamente a partir de un conjunto de diferencias culturales objetivas y/o permanentes, sino que están insertas en un proceso continuo de formación, y su desembocadura en el nacionalismo no es inevitable y sólo puede ser entendida en función de las circunstancias concretas que la animan.

2. Estas circunstancias, es decir, las condiciones bajo las cuales se produce el tránsito de la identidad étnica al nacionalismo, son las que deben ser estudiadas. Así, dentro de este marco de análisis e interpretación es como deben entenderse dos de las ideas fundamentales en su investigación:

a) La teoría de la competición de élites: explica la dinámica en la cual se produce el conflicto étnico en condiciones concretas, siempre producto principalmente de los contextos político y económico, dejando para la esfera cultural un papel muy secundario.

b) Las relaciones que mantienen las élites y el Estado son absolutamente cruciales para entender el fenómeno nacionalista en su conjunto.

Todos estos elementos teóricos se hallan interconectados en la dinámica sociopolítica y son congruentes entre sí: Ia fluidez y variabilidad de las identidades étnicas, su estado en permanente proceso constitutivo y/o formativo, permiten concebirlas como un recurso a disposición de aquellas élites que se hallan insertas en una dinámica competitiva incrustada, a su vez, en un marco político presidido por la presencia significativa de un estado moderno centralizado. Pero en este modelo no se parte de las identidades étnicas para proyectarse, sin apenas cambios, en los grupos étnicos que las élites encabezan, representan y/o gobiernan, y desembocar, finalmente, en un estado legitimado étnica y/o culturalmente. La travesía más bien es la inversa. El punto 
de inicio está en las propias élites y sus aspiraciones, y en su capacidad como tales para orientar en su beneficio los procesos políticos. El Estado puede ser concebido como contexto y como actor, pero en todo caso es un elemento activo y muy condicionante del conjunto de los acontecimientos, puesto que la actividad de las élites lo tendrá como referente permanente e ineludible. Por el contrario, la cultura y/o los rasgos étnicos en general deben ser considerados un recurso en manos de las élites, es decir, su valoración insiste en su pasividad.

\section{L os estadios étnicos hacia la nacionalidad: la formación de las naciones}

Las naciones tienen una base étnica, pero en un sentido muy concreto, el cual está lejos de cosificar o inmortalizar el pasado de las distintas comunidades étnicas. En buena medida, son las naciones las que construyen su sustrato étnico, supuestamente objetivo e inmemorial y con trascendencia política. En un sentido más estricto, la actividad desarrollada por las élites políticas, en competencia por conservar o incrementar sus beneficios y posibilidades dentro del Estado o fuera del mismo a través de la secesión y la creación inmediata de un Estado independiente, implica la incorporación y utilización de rasgos culturales encontrados en los grupos étnicos, su deformación e incluso la invención, si ello fuera necesario. D e este modo, hablar de estadios étnicos no supone la consideración de un recorrido temporal al modo de una progresión desde el pasado hasta el presente de tal forma que el primero determine o condicione fuertemente al último, aun bajo distintas circunstancias, sino la distinción de fases diferentes entre las cuales no existe una relación de progresión necesaria y en las cuales las circunstancias son tan importantes como el hecho en sí mismo. No en vano, Brass subraya la necesidad de centrar nuestra atención en torno a esas circunstancias generadoras o creadoras, y no meramente activadoras de algo que ya estaba vivo aunque dormido o expectante. Sin embargo, unos estadios deben preceder a los otros, esto es, no es posible el surgimiento de una nación si con anterioridad no ha existido una comunidad étnica, y ésta no es posible sin la presencia de un grupo o categoría étnicos. 0 tra cosa es el papel que las élites desarrollan para que esto sea realmente así. Dicho de otro modo, sin la intervención de las élites políticas no es factible pensar en la transición entre los diferentes estadios, que pueden ser resumidos en los tres momentos entre los cuales se produce el tránsito innovador: el grupo o categoría étnico, la comunidad étnica y la nación o nacionalidad. En total, esto nos da dos transiciones o fases en el desarrollo de la nacionalidad.

1. Entre la objetividad cultural y la conciencia: de los grupos o categorías étnicos a las comunidades étnicas.

La gestación de una comunidad étnica requiere la existencia previa de un grupo étnico, aunque la presencia de éste no asegure en ningún caso la evolución hacia la primera. En realidad, el grupo o categoría étnico posee un amplio conjunto de rasgos culturales objetivos que lo definen y lo personalizan, pero que por sí mismos son políticamente inertes o pasivos. En consecuencia, avan- 
zar hacia la constitución de una comunidad étnica exige la activación de un proceso de concienciación de la existencia del grupo étnico como un ente culturalmente distinto y, por tanto, con aspiraciones políticas también diferentes. D icho de otro modo, la transición entre los grupos étnicos y las comunidades étnicas es un recorrido que lleva desde el individuo hasta la agudización del valor de las relaciones que éste establece con sus semejantes, es decir, de la comunidad. Esa labor de creación de comunidades étnicas a partir de rasgos culturales dados es desarrollada por las élites políticas en competencia por una serie de beneficios comunitarios y personales dentro de unas circunstancias políticas y económicas determinadas. En primer lugar, las élites seleccionan aquellos rasgos cultural es que consideran más adecuados para diferenciar a su grupo étnico de los otros entre una gran variedad de el ementos característicos y peculiaridades con potencialidad diferenciadora. En este sentido, no existen criterios de distinción absolutos y de necesaria aparición, presencia o uso, sino que la elección de rasgos vendrá dada por las condiciones de cada uno de los casos. Se eligen lenguas y/o dialectos, ritos, religiones, símbolos, prácticas, y otros, en función de su capacidad movilizadora y cohesionadora, esto es, «the choice of the leading symbol of differentiation depends upon the interests of the elite group that takes up the ethnic cause» (Brass, 1991a, p. 30), y no de razones de perdurabilidad histórica o legitimidad y/o corrección lógica. De este modo, las comunidades étnicas son creadas a partir de la selección políticamente razonada de material es o rasgos potencialmente diferenciadores propios de los grupos o categorías étnicos de partida, o asignados a los mismos como tales ${ }^{44}$, ahora transformados en recursos políticos para las élites competidoras; pudiendo existir divergencias en la construcción simbólica y en las concepciones del grupo étnico propuestas por aquéllas. Estamos, pues, ante el proceso de formación de la identidad étnica, en cuya dinámica se verán comprometidos la existencia y la personalidad del grupo o de la categoría étnicos de referencia. En un segundo momento, las elecciones realizadas deben ser transmitidas a los miembros del grupo con el objetivo de crear, consolidar 0 cristalizar la identidad étnica y/o política que facilite y permita la concienciación sobre la propia existencia y su relevancia y la movilización sociopolítica derivada de ello. En este momento, se produce la competición política entre élites por definir las fronteras y la personalidad del grupo étnico, por delimitar los límites de la solidaridad, y con ello por determinar quiénes son sus repre sentantes legítimos, esto es, quiénes deben alcanzar el poder político. Para ello, las élites deben esforzarse en conseguir, o dar la apariencia de, una congruencia entre la multitud de símbolos del grupo étnico.

El hecho de que entre el grupo étnico y la comunidad étnica medie un proceso de selección de atributos, seguido, analíticamente, de una competencia entre élites por el triunfo o éxito de su solución, es coherente con la tesis de

44. La asignación de rasgos espurios, deformados o simplemente inventados, a grupos étnicos bajo una apariencia de naturalidad y/o autenticidad forma parte de la cotidianidad dentro de los procesos de formación de las identidades étnicas y/o políticas. 
la variabilidad de las identidades étnicas, por lo que estamos ante un proceso abierto, no obligatoriamente lineal, cuyos progresos y retrocesos no son más que la demostración de la reversibilidad de la ruta que se ha de recorrer para la consolidación de una comunidad étnica. No obstante, a pesar de la distinción efectuada de dos momentos, el de la selección y el de la competición-movilización, por razones puramente analíticas y expositivas, ambos se fusionan en la realidad y mantienen una relación fluida y continua en las dos direcciones, esto es, las decisiones adoptadas con respecto a la selección afectarán a la dinámica competitiva y a la capacidad para la movilización de los miembros de los grupos étnicos, y, a su vez, la vorágine de la competición o la lucha por el poder político y el bienestar personal y de la comunidad étnica de pertenencia revierten significativamente en la selección de rasgos culturales y en su deformación e invención. Las élites «instrumentalizan» esos rasgos culturales o étnicos, supuestamente propios, para la creación de la identidad étnica y/o política que a ellas conviene. Expresado en los términos del propio autor, «Ethnic identity formation is seen [... ] as a process created in the dynamics of elite competition within the boundaries determined by political and economic realities» (Brass, 1991, p. 16). Este elemento de constitución de la identidad étnica, o etnicidad, es verdaderamente clave, dado que su adición a, e imbricación con, un grupo o categoría étnicos nos permiten llegar al segundo estadio en el camino hacia la nacionalidad: la presencia de la comunidad étnica. Ésta existe porque un grupo concreto de gente es consciente de la diferencia, cultural o étnica, que lo separa de los otros grupos. El proceso de formación de la identidad étnica supone la manipulación y combinación de un conjunto de símbolos, a los cuales se otorga coherencia, con el objetivo de definir las fronteras de una comunidad étnica y/o nacionalidad. La articulación simbólica que fundamenta la identidad étnica se produce en un contexto de competición entre élites por la aceptación o imposición del conjunto simbólico que les favorece y les acompaña. Por tanto, la lucha está inserta en el proceso de formación de la identidad étnica. De la propuesta de Brass se deriva, más que una expresión política de la etnicidad, la construcción política de la misma, es decir, las identidades étnicas son construidas social y políticamente, están siempre abiertas al cambio y son instrumentalizadas 45 por las élites de los grupos étnicos para conseguir definir a éstos del modo más adecuado para sus intereses y obtener el control interno de sus miembros ${ }^{46}$. Es notable que la competición entre élites, principalmente, clases y grupos de liderazgo que conduce a la creación de la iden-

45. N o en vano, el propio Brass se ubica en lo que denomina la «visión instrumentalista de la formación de la identidad étnica».

46. En este sentido, las formas culturales, los valores y las prácticas del grupo étnico de referencia deben ser considerados recursos políticos en manos de las élites que se hallan inmersas en la dinámica competitiva por la definición del grupo y la defensa paralela de sus propios intereses. D e este modo, la construcción simbólica adaptada al contexto del grupo y a sus intereses que las élites promueven buscará la diferenciación y consolidar la solidaridad del grupo, siendo posible fragmentarlo para animar aquélla dentro de cada uno de los fragmentos configurados. 
tidad étnica y, con ello, de la comunidad étnica, está inserta en una dinámica caracterizada por el conflicto surgido de las pérdidas y las ganancias ${ }^{47}$ que se obtienen en relación con las distintas decisiones que se adoptan en el seno del régimen político.

D e todo lo anterior se deriva que el tránsito entre el grupo étnico y la comunidad étnica pasa necesariamente por la concienciación del grupo en cuestión, esto es, la aparición de una comunidad étnica está directamente vinculada al proceso, abierto y no necesario, de constitución y/o formación de una identidad étnica. En consecuencia, lo que se debe estudiar son las bases de la formación de estas identidades. N o obstante, únicamente bajo ciertas circunstancias los rasgos culturales objetivos se convierten en el soporte de identidades étnicas políticamente significativas. Brass resume estas circunstancias en tres categorías:

1.1. La competición de élite: está en la base del conflicto étnico que se desarrolla bajo determinadas condiciones políticas y económicas. Brass quiere dejar claro que la cultura o los valores culturales de los grupos étnicos tienen un papel menor en la génesis de la dinámica conflictiva, si bien la instrumentalización de los rasgos del grupo étnico se ve limitada por las creencias y los valores de sus miembros. No obstante, la dinámica competitiva y movilizadora contribuye a la simplificación, deformación y selección de tales creencias y valores, bajo un criterio de utilidad política, por lo que pueden sufrir una grave alteración e incluso transformación. En todo caso, la comunidad étnica o la nación naciente en ningún caso es un simple reflejo de lo previamente existente, sino una construcción políticamente orientada que puede mostrar una mayor o menor fidelidad a lo antiguo, con un nuevo sentido bajo un contexto transformado.

1.2. Las relaciones entre élites y Estado.

1.3. La movilización social y la asimilación ${ }^{48}$.

Así, la formación de la identidad étnica es un proceso abierto, y no una mera expresión de un núcleo étnico consolidado históricamente constituido, e influye en la definición del grupo étnico de partida. D e hecho, la apertura e indeterminación del proceso permite pensar que el camino desde la identidad étnica hasta el nacionalismo no sólo puede frustrarse, sino que cabe la posibilidad de mostrar el recorrido inverso o de ser considerado reversible, y ello en función de las circunstancias políticas y económicas en las que las élites deban desenvolverse.

47. Éstas, las pérdidas y ganancias, se refieren a cuestiones como la posesión del poder político, el estatus social alcanzado o esperado, Ios beneficios económicos, y otras similares que puedan resultar relevantes en cada caso concreto.

48. Brass liga, aunque no necesariamente, estas cuestiones a la urbanización y los medios modernos de comunicación de masas. 
2. El surgimiento de las naciones: de las comunidades étnicas a las nacionalidades.

El tránsito hacia la nacionalidad es el camino que lleva hacia la politización de la comunidad étnica, es decir, ésta ve reconocidos derechos propios dentro del sistema político. Alcanza, a través de la acción y la movilización políticas, un estatus peculiar caracterizado por la adquisición de derechos de tipo social, económico y político. Por tanto, las nacionalidades son comunidades étnicas que han trascendido la conciencia puramente cultural de la propia identidad para entrar de lleno en el ámbito político por medio del plante amiento de propuestas que afectan a su propia situación, de la movilización de sus miembros para su obtención y del logro final de sus metas. Una nacionalidad no es tal, o no lo es en un sentido pleno, si sus objetivos políticos no son al canzados y no consigue un cierto reconocimiento político, dado que es concebida como un estadio o una situación efectiva, siempre reversible, y no como un hecho natural que puede prescindir de los méritos o logros políticos.

La transición entre los estadios referidos, la comunidad étnica y la nacionalidad, no se produce de un modo necesario, sino que está cimentada en la actividad de las élites políticas, cuyo éxito, a su vez, está directamente relacionado con cuatro factores clave:

\subsection{La consciencia de una distribución de recursos desigual.}

El nacional ismo, para justificarse, necesita un reparto desigual de los recursos entre los diferentes grupos que componen un estado y la percepción de tal fenómeno por parte de sus miembros, pero por sí mismo el hecho de la desigualdad o de la discriminación no desencadena el desenvolvimiento de la nacionalidad. La conciencia del desplazamiento de los centros de poder y económicos puede favorecer el surgimiento y/o la consolidación de la identidad étnica, pero esto no significa que trascienda inmediatamente a la política en la forma de una lucha abierta por esos recursos que son vedados al grupo étnico en cuestión en una proporción que se considere suficiente. Para crear un movimiento nacional ista es necesaria la presencia de un sentimiento de grupo, lo cual debe ir acompañado por una construcción organizativa que el sentimiento no implica necesariamente. La percepción de la desigualdad genera las bases subjetivas para la articulación organizativa de un movimiento nacionalista, pero las condiciones materiales para su surgimiento y la dinámica política y competitiva general exceden lo puramente sentido, aunque estén directamente relacionadas con el mismo. En todo caso, el sentimiento debe estar presente como condición necesaria, aunque no suficiente, de la nacionalidad, y suele tener sus bases en el intento de miembros de un grupo étnico de acceder a posiciones políticas y/o económicas ocupadas por miembros de otros grupos. Por lo tanto, el viaje hacia la nacionalidad supone un proceso de afirmación étnica y política y la defensa de un conjunto de reivindicaciones que tratan de situar a la comunidad étnica de referencia en una posición de mayor igualdad con respecto a los grupos y/o a las comunidades étnicos dominantes. Son las nuevas condiciones de tipo tecnológico, educativo y administrativo gestadas 
junto al surgimiento del Estado centralizado y la industrialización, y las reivindicaciones de los diferentes grupos movilizados en la lucha contra su desventaja, las que debilitan o quiebran el sistema existente de distribución de los recursos y abren la posibilidad para una competición ${ }^{49}$ por los mismos en el nuevo marco sociopolítico, es decir, son las condiciones adecuadas para la generación y el desenvolvimiento del nacionalismo.

La movilización política de los sentimientos étnicos puede alcanzar una intensidad en sus ambiciones inferior a la del nacionalismo, lo que sería el comunitarismo, que trata de mejorar la capacidad competitiva de la comunidad propia y no supone un desafío tan radical a las bases mismas del reparto del poder y los recursos en la sociedad como el primero. Además, activándose por reacción, los grupos dominantes o privilegiados pueden defender sus intereses también a través de la movilización de sus miembros y del recurso a la etnicidad ${ }^{50}$.

2.2. La concienciación de la comunidad como recurso organizativo.

Si entendemos, como hace Brass, que, por definición, el nacionalismo es un movimiento político, y afirmamos que el éxito de éste depende de la presencia de un liderazgo político hábil, de los recursos necesarios y de una organización política, no es difícil comprender la importancia de valorar la relevancia que ha tenido la aparición y el fomento de un sentimiento de comunidad para el asentamiento de las bases organizativas del movimiento político nacionalista o nacionalismo. En consecuencia, la fase de concienciación es clave para el desarrollo posterior o paralelo de una organización con fines nacionalistas, condición de la creación y aparición de cualquier nacionalidad. No obstante, no debemos pensar únicamente que el sentimiento étnico conduce a la organización y a la movilización, sino que los movimientos nacionalistas influyen decisivamente a su vez en las identidades étnicas de los grupos que pretenden dirigir con exclusividad ${ }^{51}$. En línea con todo ello, sería importante, para el éxito de un movimiento nacionalista: la disponibilidad de recursos procedentes de la propia comunidad, la exclusividad o el dominio de alguna organización nacionalista en la representación de la comunidad étnica y/o nacional y la continuidad por encima del cambio de liderazgo.

2.3. La respuesta del gobierno a las demandas y reivindicaciones del grupo étnico52.

49. La competición, según Brass, está especialmente relacionada con las esferas educativa (p. e.: las escuelas) y política (instituciones de poder y gobierno).

50. La etnicidad entendida como los sentimientos étnicos.

51. Son guiados por la idea o la intención de llegar a ser los únicos representantes políticos de la comunidad.

52. Posiblemente en este punto sería más adecuado hablar de «comunidad étnica», dado que es el estadio previo a la nacionalidad y también debido a que sólo un grupo consciente de sí mismo, lo que es una comunidad étnica y no un grupo étnico, es capaz de actuar de un modo explícito en la defensa y la promoción de unos intereses que son percibidos como propios de un grupo étnico. 
El gobierno responde a través de las políticas gubernamentales, las cuales tienen la capacidad de influir sobre la actividad, la supervivencia y la definición del grupo étnico. D e este modo, las reivindicaciones políticas y económicas defendidas por los movimientos nacionalistas reciben contestación por parte del gobierno, con lo que se mantiene una relación bidireccional que debe ser entendida en el seno de una dinámica política de competencia por la atracción de recursos para cada uno de los grupos étnicos participantes.

\subsection{El contexto político general.}

En el tránsito desde la comunidad étnica hasta la nacionalidad se produce una lucha por el poder entre los diferentes grupos étnicos que participan en la dinámica de la competición, todo lo cual está directamente relacionado con al gunos aspectos relevantes del contexto político. En concreto, Brass habla de tres contextos políticos:

a) Las posibilidades para el realineamiento de las fuerzas y las organizaciones políticas y sociales.

b) La disposición favorable o buena voluntad de las élites de los grupos étnicos dominantes para compartir el poder con los líderes o élites de los grupos étnicos que aspiran a mejorar su situación política.

c) La disponibilidad potencial de escenarios políticos alternativos. En este punto es crucial el coste que supone el cambio hacia otro escenario, es decir, el pago que debe realizar el grupo étnico por acceder y/o transitar a la nueva situación ${ }^{53}$.

Todo lo anterior trata de concretar las condiciones bajo las cuales puede surgir el nacionalismo como movimiento político. En este sentido, la selección e instrumentalización ${ }^{54}$ de rasgos culturales preexistentes con una finalidad diferenciadora y cohesionadora; la competición de la élite por el poder, el estatus y la riqueza; la existencia de los medios necesarios para transmitir o comunicar los símbolos de la propia identidad dentro del grupo étnico, función integradora, y hacia fuera, función disgregadora o particularizante; la presencia de una población receptiva a los mensajes comunicativos, o lo que Brass denomina «población socialmente movilizada», y la ausencia de fracturas (cleavages) sociopolíticas que anulen o debiliten a lo étnico 0

53. La situación alternativa de nuevo cuño no tiene que ser necesariamente la independencia y la constitución de un nuevo Estado, sino que puede tratarse, según el caso, de la concre ción política o institucional de exigencias de descentralización administrativa, de autonomía política, y en todo caso pueden tener un carácter sectorial caracterizado por la incidencia sobresaliente y casi exclusiva en ámbitos determinados (p. e.: la educación).

54. D e lo que se trata, en definitiva, es de animar desde la política un cambio cultural que permita a las élites movilizar a su grupo étnico de referencia, la defensa de sus intereses y la competición con otros grupos y élites. No obstante, a pesar de la instrumentalización característica del activismo político, las élites están limitadas en su actuación por las culturas heredadas, y no cabe el uso de los rasgos seleccionados sin pensar en el conjunto y en sus significados tradicionales. 
nacional ${ }^{55}$, son las condiciones necesarias y suficientes que sientan las bases de la movilización comunitaria, y operan a modo de precondiciones del desenvolvimiento de cualquier movimiento nacionalista con verdaderas posibilidades de éxito. En consecuencia, debemos considerar dos planos. El primero es la competición entre las élites, que actúa como un activador del nacionalismo. El segundo son los factores políticos adicionales, los cuales orientarán las demandas de los nacionalistas e influirán decisivamente en su éxito.

3. El Estado y la formación de la identidad étnica.

El tránsito desde el grupo étnico a la comunidad étnica y posteriormente a la nacionalidad ha venido acompañado e influido de un modo creciente por la presencia del Estado. Es más, el nacionalismo apenas puede ser entendido sin éste, es decir, surge como una reacción ante dinámicas que se desarrollan en su seno. No en vano, el Estado, aunque relativamente autónomo, no es neutral en su configuración y actuación cotidian $a^{56}$. M ás bien, debemos pensar en su inclinación protectora, en un cierto grado, hacia grupos étnicos y clases específicos. En otros términos, el Estado favorece intereses más o menos concretos y discrimina negativamente o perjudica otros. En consecuencia, la competición entre élites, tanto dentro de cada grupo o categoría étnica como entre grupos, se enmarca en un contexto político en el cual el Estado y las políticas que desenvuelve tienen un papel crucial ${ }^{57}$. La movilización política debe ser entendida dentro de este marco de interrelaciones competitivas, en las que el Estado participa e influye. D e hecho, forma parte de la normalidad la presencia de alianzas entre el Estado y los grupos étnicos particulares ${ }^{58}$. Pero sin aban-

55. En este punto, Brass insiste sobre todo en la fractura que se deriva de la presencia social y políticamente significativa de las clases sociales.

56. N o obstante, Brass apunta que el Estado puede ser neutral en el caso de que exista conflicto entre los distintos grupos. Es significativo que el Estado pueda elegir entre una inclinación hacia la neutralidad o el partidismo, al igual que puede optar entre fomentar el pluralismo 0 la asimilación. Esta capacidad de elección nos aproxima a ideas como la de autonomía estatal.

57. D ebemos observar, siguiendo a Brass, que los cambios en el contexto político, junto a los que afectan al equilibrio de las relaciones entre el centro y la periferia (regiones), tienen una incidencia fundamental en la aparición y el desenvolvimiento de los conflictos étnicos.

58. En este punto, Brass menciona la posibilidad de referirse a la al ianza efectiva entre el Estado y subgrupos pertenecientes a clases o grupos étnicos determinados. Con ello, se quiere destacar la presencia de desacuerdos y conflictos dentro de los grupos, al margen de la diná mica competitiva intergrupal y a menudo con un grado de violencia mayor. No obstante, para los objetivos que persigo, considero suficiente la referencia a los grupos étnicos y a la competición que se desata en su interior, marginando u omitiendo las alusiones a las clases sociales, puesto que esto nos llevaría por otros derroteros que nos alejan de lo perseguido. O bviamente, a un nivel puramente intuitivo, no descarto, más bien al contrario, que las clases sociales desarrollen un papel notable en las dinámicas sociales y políticas, en los conflictos de esta índole y en la configuración de las identidades sociopolíticas de los miembros de cualquier sociedad, pero no es el motivo de la investigación que aquí desarrollo, centrada exclusivamente en el origen de las naciones y el nacionalismo y en la aportación de la etnia o la etnicidad a tal proceso de génesis. 
donar la idea de la autonomía relativa del Estado, las élites compiten por la atracción de recursos estatales o por el control del Estado mismo, incorporándose a éste y por tanto capacitándose para orientar sus políticas en direcciones muy concretas y siempre favorables a sus intereses personales y comunitarios. Sin embargo, en el lado opuesto estarían aquellas élites y/o grupos étnicos que se ven excluidos de la participación en el Estado y amenazados por unas políticas públicas con las que no se sienten identificados, no representan sus intereses y sobre las cuales apenas tienen control, si es que algún grado de control poseen. N o es extraño, por tanto, el desencadenamiento de conflictos étnicos entre los distintos grupos y las élites que compiten por controlar el aparato estatal.

Si el Estado incide sobre la competición entre élites de los distintos grupos étnicos y sobre la movilización política relacionada con ella, y la formación de las identidades étnicas se cimenta en esa dinámica competitiva y movilizadora, está claro que el Estado afecta a las identidades étnicas, e igualmente, considerando la dinámica competitiva como un proceso abierto, parece difícilmente discutible que estamos ante identidades variables 0 en flujo antes que fijas, políticas antes que culturales, actuales antes que antiguas, sometidas en todo caso a los cambios en las realidades políticas y económicas que las envuelven.

\section{Conclusiones}

¿Q ué es lo que podemos entender cuando se cataloga a un autor como modernista? Según se deriva de mi exposición previa, no demasiado. El modernismo ha incluido a un conjunto heterogéneo de autores que únicamente pueden ser reunidos en torno a la afirmación de la modernidad de naciones y nacionalismos. Sin embargo, en cierto sentido, este criterio también podría hacer referencia a la obra de Anthony D. Smith, a pesar de su intento de huida hacia el etnosimbolismo y de haber puesto una atención permanente en los fenómenos sociales y políticos premodernos como factores susceptibles de contribuir a una explicación cabal de la modernidad. En el fondo, la clave para comprender al gunos debates y aproximaciones es entender que los puntos de partida y los intereses intel ectuales son diferentes. Si referimos el concepto de nacionalismo básicamente a la ideología que tiene como núcleo duro el concepto de nación y su defensa, estaremos celebrando su modernidad desde el principio, puesto que el empleo actual de esta terminología es reciente. Si abandonamos esta perspectiva nominalista e intentamos investigar todos los fenómenos que, independientemente de su etiqueta, presentan un conjunto similar de características, posiblemente estemos sentando las bases para la discusión de su modernidad, dado que expresiones de defensa de la comunidad de pertenencia, a través de una considerable diversidad de estrategias, a nadie se le escapa que han existido y han sido presenciadas desde el principio de los tiempos. En consecuencia, no estaría de más pensar en crear clasificaciones de los autores ubicados dentro de la teoría del nacionalismo en base 
a la articulación de distintos criterios, entre los que destacaría el concepto de nacionalismo, la metodología o alguna tesis central e insoslayable. Por lo tanto, rechazo como especialmente significativa una tipología centrada única y exclusivamente en la defensa o no de la modernidad de las naciones, ya que existen notables riesgos de solapamiento hacia fuera y de disensiones hacia dentro. La exposición detallada de las dos lógicas características de las obras de Ernest G ellner y Paul Brass trataba precisamente de dejar claro el segundo punto, la heterogeneidad presente en su interior. D e este modo, este análisis quiere hacer evidente que el modernismo no concede necesariamente un papel sobresaliente a la política, entendida ésta como proceso a través del cual se generan, se encuentran, se agregan y se articulan preferencias e intereses mediante la confluencia en el espacio público de una diversidad significativa de actores individuales y colectivos sometidos únicamente a su voluntad y a las condiciones materiales de existencia. O bservando la lógica argumentativa y explicativa de ambas obras, he concluido que la política y, en este sentido, la labor de los nacionalismos y los nacionalistas forma parte inexcusable de la argumentación de Paul Brass, que empieza precisamente en este punto, es decir, qué es lo que quieren las élites políticas, como actores políticos especialmente relevantes, y cuáles son las estrategias que han decidido seguir para alcanzar aquello que se han planteado como fin en unas circunstancias concretas, siendo fundamental esto último, dado que dedica parte de su tiempo al estudio de caso, principalmente la India, y es por las condiciones que allí se dan por lo que puede estar muy directamente influido, lo cual ha incidido profundamente en la teoría. Su distanciamiento de las constricciones del pasado y no políticas es claro, en relación con lo cual defiende que el nacionalismo contribuye decisivamente a la formación de la identidad nacional y de la nación, entendiéndose aquél como un proceso de formación de identidad y/o nacionalidad. Por el contrario, G ellner desplaza la política a un segundo plano para quedarse con las condiciones que definen a la sociedad moderna e industrial como una nueva forma de organización sociopolítica que incentiva el desarrollo de comportamientos que preservan a la propia sociedad de su decadencia a través del cultivo atento de su economía. Las naciones y los nacionalismos son funcionales para ésta, siendo la base política para que cultura, Estado y economía coincidan en unidades viables o con capacidad para una supervivencia autónoma. G ellner y Brass son modernistas porque ambos propugnan la modernidad indiscutible de las naciones y los nacionalismos, pero, desde el punto de vista de la lógica explicativa, su hermandad de criterio no cubre mucho más.

\section{Bibliografía}

Brass, Paul R. (1991a). Ethnicity and N ationalism. Theory and comparison. N ueva D elhi: Sage Publications.

- (1991b). ThePolitics of India since independence. C ambridge: C ambridge University Press. 
- (1994). «Elite competition and the origins of ethnic nationalism». En BERAM EN DI, J.G.; M AIZ, R.; N ÚÑEZ, X. M . N ationalism in Europe: Past and Present. Santiago de Compostela: Universidade de Santiago de Compostela, vol. I, p. 111-126.

- (1997). «La formación de las naciones: de las comunidades a las nacionalidades». Zona Abierta, 79, p. 69-100.

BREUILLY, John (1990). N acionalismo y Estado. Barcelona: Pomares-C orredor.

Calm oun, Craig (1993). «N ationalism and ethnicity». Annu. Rev. Sociol., 19, p. 211-239.

GeLLn ER, Ernest (1972). Thought and Change. London: Weidenfeld and N icolson (1ạ edición, 1964).

- (1977). «Ethnicity and Anthropology in the Soviet U nion». Arch. europ. sociol., XVIII, p. 201-220.

- (1988). N acionesy nacionalismo. M adrid: Alianza Universidad (1ae edición en inglés, 1983).

- (1992). «N ationalism reconsidered and E. H . Carr». Review of International Studies, vol. 18, núm. 4, p. 285-293.

- (1993a). Cultura, identidad y política. Barcelona: G edisa.

- (1993b). «El nacionalismo y las dos formas de la cohesión en las sociedades complejas». En Delan Noı, G.; TAgUieff, P.-A. (comps.). Teorías del nacionalismo. Barcelona: Paidós, p. 333-365.

- (1995). Encuentros con el nacionalismo. M adrid: Alianza Editorial (1 1 a edición inglesa, 1994).

- (1996a). «T he nation: real or imagined?». N ations and N ationalism, 2 (3), p. 357-370.

- (1996b). «Reply to criticss. En H ALL, John A.; J ARVIE, Ian (eds.). TheSocial Philosophy of Ernest Gellner. Poznan Studies in the Philosophy of the Sciences and the H umanities, vol. 48. Amsterdam-Atlanta: Rodopi, p. 623-686.

- (1998). N acionalismo. Barcelona: D estino.

G UIBERN AU, M ontserrat (1996). L os nacionalismos. Barcelona: Ariel.

H ALL, John A. (ed.) (1998). The State of the N ation. Ernest Gellner and the Theory of $\mathrm{N}$ ationalism. Cambridge: Cambridge U niversity Press.

H o oBSBAW M , E.J. (1992). N aciones y nacionalismo desde 1780. Barcelona: Crítica (1a edición, 1991).

M AIZ, Ramón (1994). «iEtnia o política? H acia un modelo constructivista para el análisis de los nacionalismoss. Revista Internacional de Filosofía Política, núm. 3, mayo, p. 102-121.

- (1997a). «N acionalismo y movilización política: un análisis pluridimensional de la construcción de las naciones». Zona Abierta, 79, p. 167-216.

- (1997b). «Retos contemporáneos de la política (II): Ios nacionalismos». En ÁGUILA, Rafael del (ed.). M anual de Ciencia Política. M adrid: Trotta, p. 477-505.

M AN N , M ichael (1996). «T he Emergence of M odern European N ationalism». En H ALL, John A.; J ARVIE, Ian (eds.). The Social Philosophy of Ernest G ellner. Poznan Studies in the Philosophy of the Sciences and the H umanities, vol. 48. AmsterdamAtlanta: Rodopi, p. 147-170.

M IN OGUE, Kenneth (1996). «Ernest Gellner and the Dangers of Theorising N ationalism». En H ALL, John A.; J ARVIE, I Ian (eds.). The Social Philosophy of Ernett Gellner. Poznan Studies in the Philosophy of the Sciences and the H umanities, vol. 48. Amsterdam-Atlanta: Rodopi, p. 113-128.

N AIRN , Tom (1997). Faces of Nationalism. Janus Revisited. Londres: Verso. 
O 'LeARY, Brendan (1996). «On the $\mathrm{N}$ ature of $\mathrm{N}$ ationalism: An Appraisal of Ernest G ellner's Writings on Nationalism». En H ALL, John A.; J ARVIE, I an (eds.). The Social Philosophy of Ernest Gellner. Poznan Studies in the Philosophy of the Sciences and the H umanities, vol. 48. Amsterdam-Atlanta: Rodopi, p. 71-112.

SCRUTON, Roger (1996). A Dictionary of Political Thought. Londres: M acmillan (1 1 edición en inglés, 1982).

SM ITH, Anthony D . (1986a). TheEthnic O rigins of N ations. O xford: Basil Blackwell.

- (1991). National I dentity. H armondsworth: Penguin.

- (1995b). «G astronomy or geology? The role of nationalism in the reconstruction of nations». Nations and N ationalism, 1 (1), p. 3-23.

- (1996a). «H istory and M odernity: Reflection on the Theory of $\mathrm{N}$ ationalism». En H ALL, John A.; J ARVIE, Ian (eds.). The Social Philosophy of Ernest G ellner. Poznan Studies in the Philosophy of the Sciences and the H umanities, vol. 48. AmsterdamAtlanta: Rodopi, p. 129-146.

- (1996e). «M emory and modernity: reflections on Ernest G ellner's theory of nationalism». N ations and N ationalism, 2 (3), p. 371-388.

- (1998). Nationalism and M odernism. Londres: Routledge.

SM ITH, Anthony D.; H UTCHIN SON , John (2000). Nationalism. Critical Concepts in Political Science. Londres: Routledge, 5 volúmenes.

StARGARDT, N icholas (1996). «G ellner's N ationalism: The Spirit of M odernisation?». En H ALL, John A.; J ARVIE, Ian (eds.). TheSocial Philosophy of Ernest Gellner. Poznan Studies in the Philosophy of the Sciences and the H umanities, vol. 48. AmsterdamAtlanta: Rodopi, p. 171-189. 